\title{
Situación de necesidad económica y Seguridad Social: el Ingreso Mínimo Vital como eje de la tutela
}

\author{
Situation of economic need and Social Security: the Minimum \\ Vital Income as the axis of guardianship
}

\author{
Susana Barcelón Cobedo* \\ Universidad Carlos III de Madrid \\ ORCID ID: 0000-0003-3040-5079
}

doi: https://doi.org/10.20318/labos.2020.5779

\section{Consideraciones generales}

Aunque oscurecido por la catarata de Reales Decretos Leyes de contenido laboral y de protección social aprobados durante el estado de alarma, el Real Decreto Ley 20/2020, de 29 de mayo, por el que se establece el Ingreso Mínimo Vital (a los que se hará referencia aquí como RDL 20/20 e IMV, respectivamente) es, sin duda alguna, una norma de particular relevancia en el ámbito de la Seguridad Social. Siquiera sea porque, a diferencia de esos otros Reales Decretos Leyes que introducen reglas excepcionales de vigencia temporal vinculada a la existencia del estado de alarma y de sus secuelas, el RDL 20/20 es una norma con vocación de permanencia en cuanto que el IMV que crea es una prestación que, sin negar que ha recibido un impulso significativo por las especiales circunstancias de crisis social y económica provocadas por la pandemia, tiene la finalidad de afrontar, de manera definitiva, un déficit del ámbito de protección del Sistema español de Seguridad Social que se ha mantenido como tal desde que en el año 1990 se hizo un diseño restrictivo del abanico de las prestaciones no contributivas.

Más concretamente ese déficit consistía en la ausencia de tutela de quienes, careciendo de los recursos mínimos indispensables para subvenir a sus necesidades más elementales, ni eran personas mayores de 65 años, ni discapacitadas en un grado igual o superior al 65 por ciento, ni tampoco eran desempleados, con edades comprendidas entre los 18 y los 65 años, que pudieran acceder a la variada gama de prestaciones por desempleo o asimiladas de naturaleza asistencial. Situaciones que sí están cubiertas por las pensiones no contributivas de invalidez o de jubilación y, de forma temporal y con limitaciones, por alguna de esas prestaciones de desempleo, entendidas en sentido amplio al abarcar desde el subsidio asistencial hasta las prestaciones extraordinarias de desempleo vinculadas a programas de activación pasando por la renta activa de inserción o la renta agraria.

La relevancia, por tanto, del RDL 20/20 consiste en que crea una nueva prestación que se suma a las que ya proporciona el Sistema español de Seguridad Social, tal y como se evidencia en la nueva redacción que se da al art. 42, dedicado a establecer la acción protectora del Sistema de Seguridad Social, del Real Decreto Legislativo 8/2015, de 30 de octubre, por el que se aprueba el texto

‘barcelon@der-pr.uc3m.es 
refundido de la Ley General de la Seguridad Social (LGSS, en lo sucesivo), incluyendo al IMV en el repertorio de prestaciones. De esta forma, el RDL 20/20 hace finalmente realidad el compromiso establecido en el art. 41de la Constitución Española (CE) en relación con el ámbito objetivo o material de protección de la Seguridad Social, pudiendo afirmarse que el Sistema de Seguridad Social es ahora verdaderamente universal ya que protege, sea por la vía contributiva como, en particular, por la no contributiva, las situaciones de necesidad económica que pueden afectar a los ciudadanos.

Dada esta finalidad, el RDL 20/20 no es, como se ha dicho, una norma provisional dictada para hacer frente a situaciones excepcionales mediante instrumentos, igualmente singulares y temporales, sino que, por el contrario, se dicta para cerrar definitivamente esa brecha en el Sistema de Seguridad Social constituida por la carencia de una protección económica mínima ofrecida de manera universal a todos los ciudadanos que se encuentren en una situación real de necesidad económica y al margen, pues, de la existencia de una discapacidad o de una edad avanzada. Una fisura que hasta ahora ha obligado a admitir que el Sistema español de Seguridad Social no era plenamente universal y que, por tanto, tampoco se realizaba en su totalidad el mandato del art. $41 \mathrm{CE}$ ya que, según dicho artículo y como es sabido, los poderes públicos están obligados a garantizar una protección suficiente a todos los ciudadanos que se encuentren en una situación de necesidad económica. Lo que sin duda ocurre cuando hay una carencia real, efectiva y probada de ingresos o recursos que impide al sujeto afectado atender las necesidades básicas de subsistencia tanto de sí mismo como de la unidad de convivencia de la que forma parte.

\section{El IMV no es una Renta Básica}

La aprobación del RDL 20/20 ha estado precedida de abundantes debates, no solo en España, sobre la adecuación o conveniencia de la implantación por parte de los poderes públicos de una prestación económica que garantice al ciudadano unos recursos mínimos. Debates en los que se han manejado muchas denominaciones tales como renta básica, renta ciudadana, renta mínima, salario social, renta de inserción, renta de solidaridad, o ingreso mínimo garantizado, entre otras muchas semejantes. Sin embargo, esta selva de denominaciones no puede ocultar una diferencia esencial que separa tales prestaciones en dos grupos claramente diferenciados.

Así, de una parte, cabe agrupar todas las prestaciones establecidas para proporcionar cobertura económica a las personas o a los núcleos de convivencia que carecen, efectiva y realmente, de los recursos mínimos para la subsistencia. Una situación de necesidad a la que se refiere, por ejemplo, el Pilar Europeo de Derechos Sociales (Gotemburgo, 2017) cuando, entre los veinte principios fundamentales que establece, destaca el principio 14 donde se declara que toda persona que "carezca de recursos suficientes" tiene derecho a una renta mínima que permita una vida digna. Esto es, una prestación que, con independencia del nombre que se le asigne, se articula para hacer frente a una situación real de necesidad o de pobreza consistente en la incapacidad del sujeto de obtener los ingresos mínimos necesarios para poder subsistir dignamente.

Es evidente que este tipo de prestaciones, que se han venido a calificar como "prestaciones de garantía de rentas de subsistencia" (AAVV. Las prestaciones de garantía de rentas de subsistencia en el Sistema español de Seguridad Social (dir. S. González Ortega), Tirant lo Blanch, 2018), suscitan de inmediato cuestiones, conceptos y categorías complejas y frecuentemente problemáticas como son, entre otras, la noción de carencia de recursos suficientes o, lo que es lo mismo, el propio concepto de pobreza y la forma de establecerla; lo relativo al referente subjetivo para la medida de la pobreza, si individual o grupal y, en este segundo caso, qué personas integran el grupo aspirante a la protección; los ingresos que se computan, caso de tenerlos el solicitante y los miembros de su unidad de 
convivencia, y la forma de hacerlo; los medios de prueba de la situación de necesidad; la determinación de la cuantía de la prestación que inevitablemente depende de lo que se considere necesario para una supervivencia mínima y el impacto sobre ella de la naturaleza individual o colectiva del potencial beneficiario; $y$, en fin, las condiciones para el mantenimiento del derecho a la prestación o, desde el punto de vista contrario, las circunstancias que determinan su pérdida, empezando justamente por el hecho de no encontrarse ya en la situación de necesidad por haber logrado obtener ingresos suficientes para subsistir.

Frente a este grupo de prestaciones de garantía de rentas de subsistencia, se ha hablado de otras cuyos rasgos definitorios las diferencian de las anteriores. Son las que suelen calificarse como renta mínima, renta ciudadana o, más habitualmente, renta básica.

En este segundo grupo se encuentran prestaciones sociales de carácter económico cuya justificación no se encuentra en la pobreza, confirmada y mantenida, del sujeto aspirante a la tutela, sino que se legitiman básicamente por el hecho de la ciudadanía ya que se trata de una prestación que se proporciona a todos los ciudadanos sin distinción y con la sola condición de la nacionalidad. El objetivo central de estas prestaciones es prevenir que la situación de pobreza nunca llegue a materializarse articulándose, en consecuencia, como un mecanismo de prevención de exclusión social. Por eso el derecho a la prestación se califica como un derecho de ciudadanía del que son titulares todos los ciudadanos por el hecho de serlo y con independencia de si trabajan o no y de si reciben o no ingresos por su actividad profesional, así como de si son titulares de algún patrimonio y de las rentabilidades del mismo. Para otorgar la prestación es, por tanto, central, y único requisito, el ser ciudadano del país de que se trate.

No obstante, lo habitual es que a esa exigencia se sume la de estar residiendo, o haber residido un número mínimo de días, meses o años en el país en el que se solicita la prestación como expresión de la pertenencia del sujeto a la comunidad política de la que pide un ejercicio de solidaridad. Una circunstancia tan relevante que incluso puede desplazar a la nacionalidad otorgando la tutela también a ciudadanos de otros países, mucho más si comunitarios, con la sola condición de probar su vinculación con el país de que se trate mediante precisamente una residencia previa mínima y su mantenimiento mientras la prestación se perciba. Como también puede exigirse, sin alterar la esencia de la prestación, una edad mínima habitualmente identificada con la mayoría de edad. En todo caso, se trata de una prestación universal e incondicionada ya que no queda sujeta, como las del anterior grupo, a la condición de recursos o a la existencia de una situación efectiva de necesidad económica. Todo ciudadano o residente, por el hecho de serlo, tendría derecho a dicha renta básica en tanto que la misma no tiene como finalidad directa reparar la contingencia en que se materializa en un sujeto que encuentra en una situación de necesidad real.

Pero no es el momento ni el lugar para introducir el debate, siempre complejo y no exento de dificultades técnicas, acerca de las ventajas e inconvenientes, tantos sociales como económicos o jurídicos e incluso organizativos o de gestión, de la renta básica frente al conjunto de prestaciones de corte asistencial dirigidas a paliar las situaciones marcadas por la carencia de recursos. Baste aquí con subrayar que el IMV, tal y como está diseñado en el RDL 20/20, pertenece al grupo de las prestaciones de garantía de rentas de subsistencia como lo declara expresamente el art. 1 RDL 20/20 al establecer que su finalidad es crear y regular una prestación que está orientada a "prevenir el riesgo de pobreza y exclusión social" de quienes "se encuentren en una situación de vulnerabilidad por carecer de recursos económicos suficientes para la cobertura de sus necesidades básicas". No cabe, pues, identificar el IMV con la renta básica que es universal (derecho de ciudadanía) e incondicional (no sometida a prueba de recursos).

Sin duda alguna que los obstáculos, dificultades e incertidumbres de todo tipo, incluso políticas, asociadas al establecimiento de una renta básica ha empujado al legislador a elegir el camino más habitual y menos conflictivo, aun siéndolo en todo caso tal y como como se ha puesto de ma- 
nifiesto en las opiniones descalificadoras de esta iniciativa sostenidas por determinados grupos políticos. Tal camino ha sido el de ańadir una prestación más al repertorio de las no contributivas cuyo otorgamiento se funda precisamente en la existencia de una situación real de necesidad económica. Teniendo para ello el apoyo del art. $41 \mathrm{CE}$ y la legitimación que procede de la indiscutible función de lucha contra la pobreza que el IMV cumple de forma directa, sumándose a otras prestaciones de la misma naturaleza que ya existen tanto dentro del Sistema de Seguridad Social (concretamente, las que integran el nivel asistencial de desempleo así como las no contributivas de jubilación e invalidez) como fuera del mismo, como sucede con las prestaciones autonómicas de garantía de rentas con las que el IMV tiene un evidente, cercano y notable parentesco.

\section{El IMV como prestación de la Seguridad Social: el rescate de un territorio abandonado}

Se acaba de hacer referencia las prestaciones autonómicas de garantía de recursos de subsistencia que, vigentes desde hace más de treinta años, han venido cubriendo el déficit del Sistema estatal de Seguridad Social al que se ha hecho referencia al inicio. De manera que, en la medida en que dicho Sistema no protegía todas las situaciones de necesidad económica real en que pudieran venir a encontrarse los ciudadanos, las Comunidades Autónomas (CCAA) han venido ocupando esos resquicios o fracturas del Sistema ofreciendo, precisamente a quienes no conseguían protección del mismo pese a encontrarse en una situación de necesidad económica, unas prestaciones económicas de garantía de rentas de subsistencia que han venido recibiendo denominaciones muy variadas tales como rentas de solidaridad, de inserción o rentas mínimas. De forma que la universalidad subjetiva de la protección social era el resultado de la suma de la acción de la Seguridad Social, sobre la base del art. $41 \mathrm{y}$ del art. 149.1.17 a CE, y de la actividad de las CCAA, éstas a partir del fundamento constitucional contenido en el art. 148.1.20 ${ }^{\text {a }} \mathrm{CE}$, relativo a la Asistencia Social.

Pero la diversidad de regulaciones y su ámbito de aplicación, limitado al territorio de cada $\mathrm{CA}$, además de constituir una discutible renuncia del Estado a asumir su tarea de garantizar mediante la Seguridad Social la tutela de una situación de necesidad que indudablemente le correspondía conforme a lo exigido en el art. $41 \mathrm{CE}$, tampoco garantizaba la igualdad de todos los ciudadanos en cuanto al ejercicio de sus derechos fundamentales (algo que han puesto de manifiesto los estudios, obra del grupo de investigación sobre estas cuestiones radicado en la Universidad Carlos III, incluidos en el número monográfico de la Revista Temas Laborales, núm. 143/2018). Lo que reclamaba una acción estatal que, materializando el compromiso del Estado en la garantía de una tutela general de las situaciones de necesidad económica, mucho más si éstas son reales y efectivas, exigido por el art. $41 \mathrm{CE}$, garantizara la igualdad de todos los españoles. Razón por la que, como lo explicita la disposición final novena del RDL 20/20, la iniciativa estatal estaba requerida igualmente por el art. 149.1.1 a CE que obliga al Estado a garantizar dicha igualdad en todo el territorio nacional. Todo lo cual pone de manifiesto una de las dimensiones más significativas del RDL 20/20, cual es la de reconstruir el esquema competencial diseñado por la $\mathrm{CE}$, reubicando los roles respectivos de Estado y CCAA.

Ejemplo de ello es la clara y directa reivindicación que el art. 2.2 RDL 20/20 hace de la competencia estatal para afirmar, basándose en los títulos competenciales contenidos en el art. 149.1. $1^{\text {a }}$ y 149.1.17a $\mathrm{CE}$, que es función del Estado, en desarrollo del art. $41 \mathrm{CE}$, proteger la situación de necesidad que se describe en el art. 1 como de vulnerabilidad económica. Lo que hace mediante la aprobación del IMV y su inclusión en el repertorio de las prestaciones no contributivas del Sistema de Seguridad Social que es, en cuanto a su legislación básica y a su régimen económico, competencia del Estado. Sin que ni siquiera se someta a discusión que la regulación del IMV, en 
todos sus rasgos y como se acepta respecto de todas las prestaciones de la Seguridad Social, constituye legislación básica. Lo que lleva a declarar, también en el apartado 2 del art. 2, que el IMV, como prestación estatal de Seguridad Social, es compatible con las ayudas que puedan establecer las CCAA en uso de sus propias competencias en el ámbito de la protección social, que se anclan en el art. 148.1.20 $\mathrm{CE}$, donde se menciona, en clara contraposición con la Seguridad Social, a la Asistencia Social.

No es éste el lugar para reproducir la interminable y nunca bien resuelta confrontación conceptual entre Seguridad Social y Asistencia Social como títulos de atribución de competencias, sea al Estado sea a las CCAA. Baste señalar ahora que, en la medida en que el RDL 20/20 considera que una prestación como el IMV es de competencia estatal por ser Seguridad Social, está delimitando un territorio en el que las CCAA no pueden penetrar salvo, claro está, por la vía de las ayudas o prestaciones complementarias. De aquí que posiblemente con toda intención, el art. 2.2 hable de "ayudas que puedan establecer las Comunidades Autónomas". Es indudable que ello implica, a su vez, una reivindicación de su competencia por parte del Estado, reubicando así la actividad que las CCAA, aprovechando la pasividad del Estado y su falta de voluntad en completar constitucionalmente el ámbito subjetivo de protección del Sistema de Seguridad Social, han venido desempeńando para atender las situaciones de pobreza.

Varios son los caminos conforme a los cuales puede obtenerse este resultado. Uno, permitiendo expresamente que las CCAA sigan concediendo ayudas que complementen el IMV y sin que de la afirmación del art. 2.2, pueda deducirse un propósito beligerante del Estado en el sentido de aprovechar la creación del IMV para eliminar todas las rentas autonómicas que, con rasgos prácticamente iguales, continúan otorgando las CCAA. Un propósito de momento excluido, entre otras cosas porque podría ser el origen de un interminable conflicto competencial. Otra vía es la de considerar incondicionalmente compatibles con el IMV los salarios sociales, rentas mínimas de inserción o ayudas análogas de Asistencia Social concedidas por las CCAA, como expresamente lo dice el art. 7.1, c) del RDL 20/20. Con este tratamiento, lo que el art. 7 hace es señalar una prevalencia del IMV sobre las rentas autonómicas de forma que el INSS, que es la que el art. 22 RDL 20/20 hace la Entidad Gestora típica del IMV, solo ha de preocuparse de la compatibilidad en relación con sus propias prestaciones, siéndole indiferente si el perceptor del IMV también consigue de su CA una prestación social similar.

Lo anterior significa que el RDL 20/20 se limita a desplazar la cuestión hacia las CCAA, que deberán valorar si introducen o no en su normativa, conservando la vigencia de sus rentas mínimas, alguna regla que establezca que quienes perciben el IMV ya no podrán acceder a ellas. Algo para lo que posiblemente se verán incentivadas por el desplazamiento del gasto que ello implica hacia la Seguridad Social y el Estado; y porque de esta forma podrán reconducir los recursos que hasta ahora venían destinando a sus prestaciones autonómicas adscribiendo así a dichas prestaciones mucho más claramente en el concepto de ayuda a que se refiere el art. 2.2 del RDL 20/20.

Aunque parezca algo relacionado con la mera gestión, no puede olvidarse finalmente que el RDL 20/20 llama a las CCAA, y también a los entes locales, a tener un protagonismo particular en el tratamiento del IMV, reproduciendo respecto de las primeras los acuerdos, más que consolidados, que han acabado atribuyéndoles la gestión plena de las pensiones no contributivas de invalidez y jubilación. Una alternativa que el RDL 20/20 prevé en el art. 22, más allá de las atribuciones directas en esta materia a las CCAA de Navarra y del País Vasco contenidas en la disposición adicional quinta. De manera que, finalmente, será el Estado, a través de la Seguridad Social, quien regule y financie el IMV, pero serán las CCAA, con la ayuda de los entes locales, las que los tramiten y resuelvan. Una razón más para que las CCAA no se consideren particularmente agredidas por esta recuperación normativa de una competencia que ahora, y siempre, ha sido estatal. 


\section{La ubicación del IMV dentro del Sistema de Seguridad Social}

La nueva redacción de los arts. 42.1, c) y 109.3, b) LGSS por obra de la disposición final cuarta del RDL 20/20 incluye al IMV en el repertorio de las prestaciones que integran la acción protectora del Sistema de Seguridad Social (art. 42) y lo ubica, a afectos de financiación, en el grupo de las prestaciones no contributivas junto a otras prestaciones económicas como las pensiones no contributivas de invalidez y jubilación, el subsidio no contributivo de maternidad, los complementos de mínimos y las prestaciones familiares (art. 109 LGSS).

Se trata de una ubicación natural si se tiene en cuenta que la contingencia protegida es la carencia efectiva de recursos, o el hecho de no obtenerlos por encima de un cierto nivel, sea de pobreza absoluta o relativa; además de que el título legitimador del derecho no es una aportación financiera previa al Sistema de Seguridad Social, que es indiferente si ha existido o no salvo que sirva para generar una prestación contributiva, incompatible, dicho sea de paso, con el IMV, sino la nacionalidad y/o la residencia asociada a esa carencia de ingresos. En consecuencia, y siendo el IMV una expresión de solidaridad general, es igualmente lógico que su financiación corra a cargo de los Presupuestos Generales del Estado donde deberán consignarse anualmente las aportaciones finalistas del Estado al Presupuesto de la Seguridad Social.

Pero la ubicación legal del IMV en el nivel no contributivo de prestaciones del Sistema de Seguridad Social no significa simplemente un añadido más a un listado que poco a poco se va haciendo más amplio. Por el contrario, la creación del IMV tiene una trascendencia mayor dentro del Sistema; tanta como que, dadas sus características, el tipo de protección y el universo subjetivo al que se dirige, tiene la potencialidad de convertirse en la prestación central y más relevante de dicho nivel. Un ejemplo inicial de esta funcionalidad se encuentra en el hecho, por ejemplo, de que la aprobación del IMV ha puesto en marcha un proceso de absorción de otras prestaciones, en concreto de la prestación por hijo o menor a cargo no discapacitado que es una prestación familiar estándar no contributiva dirigida a personas con hijos o menores a cargo que no tuvieran ingresos por encima de un cierto nivel de pobreza relativa. Y ello, aunque el proceso de absorción, que se evidencia en la supresión de dicha prestación del repertorio de prestaciones familiares contenido en el art. 351 LGSS por obra de la misma disposición final cuarta RDL 20/20, se haya articulado de una forma un tanto confusa y poco solvente desde el punto de vista técnico como lo manifiestan las disposiciones transitorias primera y séptima del mismo RDL 20/20.

La importancia de esta absorción puede calibrarse teniendo en cuenta que con ella el IMV ha propiciado que las prestaciones familiares, aun siendo no contributivas por estar dirigidas al conjunto de la ciudadanía y sin que el desempeño profesional suponga un filtro de ninguna especie, han perdido su naturaleza de asistenciales, en el sentido de prestaciones dependientes de la existencia de una situación de pobreza del tipo que sea. Por el contrario, se configuran a partir de ahora como derechos de ciudadanía que se reconocen en razón de la condición de discapacitado del hijo a cargo (es decir, son en realidad prestaciones no condicionadas a prueba de recursos dirigidas a tutelar a las personas discapacitadas) o del hecho de un acontecimiento puntual que implica un incremento importante de gastos como sucede con las indemnizaciones por parto en los supuestos de parto múltiple, nacimiento o de adopción en los casos de familias numerosas, madres discapacitadas, o familias monoparentales (tratándose de prestaciones de ayuda, igualmente incondicionadas, para hacer frente a un incremento de la carga familiar, al menos en sus primeros momentos ya que se trata de prestaciones a tanto alzado).

Ahora bien, la depuración que la creación del IMV implica en relación con las prestaciones no contributivas no se queda aquí ya que, presumiblemente, también sucederá con las diversas prestaciones por desempleo asistencial. En efecto, aunque sean indirectamente contributivas ya que en la práctica generalidad de los casos únicamente se puede acceder a ellas si se ha trabajado y cotizado 
previamente por desempleo e incluso si se han percibido y agotado las prestaciones por desempleo del nivel contributivo, sin embargo, también exigen, como sucede con el IMV, que el solicitante carezca de los recursos mínimos para la subsistencia; es decir, tienen naturaleza asistencial cumpliendo una función semejante a la del IMV aunque eso sí, estrechamente vinculada con las medidas de activación y de retorno al mercado de trabajo que, por ahora y a la espera del futuro desarrollo reglamentario, solo están enunciadas en el RDL 20/20.

No obstante, y pese a esa dosis de identidad, lo cierto es que el IMV se presenta como una prestación más abierta en la medida en que solo requiere la carencia de recursos, mientras que el acceso a las prestaciones asistenciales de desempleo está fuertemente condicionado por requisitos muy variados, como así se manifiesta por ejemplo en la disposición adicional vigesimoséptima LGSS respecto del llamado subsidio extraordinario por desempleo. Y ello, aunque su percepción quede finalmente condicionada a exigencias similares a las que se imponen al disfrute tanto del subsidio por desempleo, de la renta activa de inserción o del subsidio extraordinario por desempleo como son la disponibilidad para el trabajo, la obligación de aceptar uno adecuado o el sometimiento a acciones de formación o de recualificación que incrementen la empleabilidad del sujeto.

A esta finalidad depuradora de prestaciones que el IMV puede cumplir ayuda el que ambas prestaciones tienen cuantías muy similares. Esto es así ya que, aunque en el caso de las prestaciones asistenciales por desempleo dicha cuantía sea equivalente al 80 por 100 del Indicador de Rentas de Efectos Múltiples (IPREM) y el IMV se determine mediante una cuantía fija anual establecida en la Ley de Presupuestos, el resultado final arroja cifras muy parecidas. Una escasa diferencia que no habrá de ser un obstáculo, o de serlo será secundario, para una eventual absorción por parte del IMV de las prestaciones asistenciales de desempleo.

Además de las prestaciones familiares y de las asistenciales por desempleo es claro que el IMV se confronta directamente con las actuales pensiones no contributivas de invalidez y jubilación con las que comparte muchos aspectos de su regulación, empezando, aquí sí, por la cuantía. Esta identificación propiciará, sin duda, movimientos de unificación de forma que las pensiones pueden acabar absorbidas por el IMV, aunque dentro de él conserven algunas peculiaridades en relación, por ejemplo, con las medidas de activación profesional, que no podrán serles lógicamente exigidas dada la imposibilidad representada por la edad y el alto nivel de discapacidad. Pero esta exclusión también podría plantearse desde la perspectiva del IMV respecto de otros colectivos como los desempleados de larga duración, o los desempleados con muy limitada opciones reales de recolocación debido a la edad, el nivel de conocimientos y de experiencia profesional, su adaptabilidad o a la existencia de limitaciones funcionales correspondientes a niveles de discapacidad relevantes, aunque no sean los más elevados.

De producirse los movimientos descritos, el IMV acabará convirtiéndose en la prestación ordinaria, general o estándar (y puede que única) establecida dentro del Sistema de Seguridad Social para dar cobertura a la carencia de recursos y a la que, existiendo dicha carencia, cualquier ciudadano o residente pueda acceder sin que la edad, la discapacidad o la trayectoria profesional pueda suponer una exigencia cuyo incumplimiento excluya de la protección, aunque sí pueda modularla. Su configuración como derecho subjetivo, que es otra de las aportaciones del RDL 20/20, ayudará sin duda a esta consolidación y centralidad del IMV dentro del nivel no contributivo de prestaciones del Sistema.

\section{Los rasgos identificatorios del IMV: la centralidad de la unidad de convivencia y la vulnera- bilidad económica como nueva contingencia del Sistema de Seguridad Social.}

Tratándose de una nueva prestación es interesante establecer los rasgos que la identifican, muchos de ellos característicos de otras prestaciones anteriores, como sucede con las rentas mínimas auto- 
nómicas que, sin lugar a dudas, han servido de inspiración directa para la regulación contenida en el RDL 20/20. De entre esos rasgos hay que destacar la peculiaridad del sujeto protegido que, más allá de la persona individual, es típicamente el conjunto de personas que se agrupan en unidades de convivencia y que comparten domicilio, así como los ingresos y gastos de todos sus miembros.

Esta peculiaridad del sujeto protegido, marcada por la centralidad de la unidad de convivencia, se proyecta sobre todos los elementos de la regulación. Sea sobre la solicitud, que siendo individual debe ir suscrita por los demás miembros mayores de edad integrantes de la unidad de convivencia; sea sobre los ingresos computables para los que igualmente habrá de valorarse los de la unidad de convivencia; sea sobre la cuantía de la prestación que está determinada por la composición concreta de la unidad de convivencia; sea sobre las obligaciones y cargas que se proyectan no solo sobre el solicitante sino sobre el conjunto mayor de edad, incluida la responsabilidad solidaria frente a la reclamación de prestaciones indebidamente percibidas.

De modo que la trascendencia de la unidad de convivencia convierte a los artículos destinados a delimitarla, sin duda, en uno de los más importantes de la norma. Se trata de una regulación que ya se vislumbra compleja desde el propio art. 4 cuando define al sujeto beneficiario de esta prestación diferenciando, por un lado, a los integrantes de una unidad de convivencia; y por otro, a las personas que vivan solas con una edad comprendida entre los 23 ańos y menor de 65 ańos, siempre que en este caso reúnan la condición de no estar integradas en otra unidad de convivencia.

Pues bien, la primera idea que surge tras la lectura de la norma es que no es posible hablar de un único tipo de unidad de convivencia. Más concretamente, el art. 6.1 se refiere a ésta como la constituida por todas las personas que residan en un mismo domicilio y que estén unidas entre sí por vínculo de matrimonio o como pareja de hecho (en los términos previstos en el art. 221.2 LGSS para la pensión de viudedad), o por vinculo de afinidad o consanguinidad hasta el segundo grado, y otras personas con las que conviva en virtud de guarda con fines de adopción o acogimiento familiar permanente. La descrita es la que podemos calificar de unidad de convivencia típica, en tanto que la razón de la unión es la convivencia en el mismo domicilio de personas con vínculos familiares, sea por matrimonio/pareja de hecho legal, o parentesco hasta el segundo grado. Se trata, en definitiva, de una integración obligatoria en unidades de convivencia por el doble hecho de compartir domicilio y tener entre sí lazos concretos que manifiestan la vinculación de las personas más allá del hecho de compartir el domicilio; que es un requerimiento básico, pero no suficiente. Elementos ambos que expresan que esa unidad de convivencia funciona como una unidad o comunidad patrimonial cuyo estado económico conjunto, y no el de los individuos aislados que la integran, determina la apreciación de que se trata de un hogar aquejado de pobreza y que, como tal hogar o espacio físico que da acogida a una colectividad, debe ser protegido.

Desde esta perspectiva, parece claro que quien comparte domicilio con personas que, a los efectos del IMV son irrelevantes o invisibles por no formar parte del grupo de personas vinculadas por los lazos familiares antes descritos, no pueden unirse al demandante de la solicitud del IMV para constituir una unidad de convivencia. Una expulsión o la producción de miembros invisibles de las unidades de convivencia que obviamente tiene, como contrapartida, que, si tales personas tienen entre sí lazos de los que el art. 6.1 RDL 20/20 considera determinantes para la existencia de una unidad de convivencia, el solicitante no podrá excluirlos de la solicitud por lo que ésta no será ya individual sino forzosamente en nombre de la unidad de convivencia que, a efectos del RDL 20/20, debe necesariamente presentarse como tal ante el INSS.

Pues bien, el RDL 20/20 no es ajeno a la posibilidad de que puedan existir otro tipo unidades de convivencia, y a tal fin, obliga a los solicitantes, ahora ya sin lazos entre sí y que comparten domicilio, a presentarse como colectivo, constituyendo una unidad de convivencia atípica, reconocida como tal en el art. 6.2, c). Lo que significa que dentro de las atípicas quedan comprendidas las unio- 
nes por razones de amistad o semejante (tema sin duda complejo que está pendiente de desarrollo reglamentario) pero también las de parentesco por afinidad o consanguinidad de tercer o más grado así como los supuestos de excónyuges o ex parejas de hecho legal o los casos de parejas de hecho que no estén debidamente constituidas en los términos del art. 221.2 LGSS para la pensión de viudedad que exige una convivencia previa acreditada de cinco ańos e inscripción en el correspondiente registro de dos años como tal pareja de hecho.

La unidad de convivencia se presenta así como como un imán que atrae hacia ella a quienes comparten domicilio, sea con motivo de un vínculo familiar $\mathrm{u}$ otras razones; pues, existiendo vínculos familiares de los legalmente previstos (matrimonio/pareja de hecho, parentesco hasta el segundo grado), la unidad de convivencia típica siempre absorberá a quien los tuviera y decidiera compartir domicilio con ella. Y de la misma forma, tal absorción habría de suceder con quienes carecen de ellos, pero igualmente quieren compartir domicilio bien sea porque el parentesco es de tercer grado, la pareja de hecho no es legal o simplemente se trata de personas unidas por razones de amistad, entre otras, ya que se trata de un tema pendiente de desarrollo reglamentario.

Junto a la unidad de convivencia, otro elemento propio del IMV, que ahora sí comparte con otras prestaciones asistenciales, es la de la situación de necesidad protegida que es, como se viene repitiendo, de carencia de recursos. Una carencia de recursos que de forma directa y muy expresiva el RDL 20/20 denomina en términos de vulnerabilidad económica y que sintéticamente condensa la situación de necesidad en la carencia o insuficiencia de recursos para hacer frente a las necesidades más elementales de la vida y de la propia subsistencia. Vulnerabilidad económica que no debe identificarse con la situación de pobreza o indigencia absoluta; antes al contrario, lo que se reclama es que la persona no alcance un nivel mínimo de ingresos que le permita vivir dignamente, el habitualmente calificado como umbral de pobreza, por debajo del cual puede decirse que la persona en cuestión se encuentra en una situación de necesidad económica.

Se podría decir que, en este extremo, la norma no aporta ninguna novedad ya que sigue la pauta habitual para este tipo de prestaciones de corte asistencial tal y como sucede con las no contributivas del Sistema; de forma que ese umbral se identifica cuantitativamente con la propia prestación en la idea de que si de lo que se trata es de garantizar un nivel de recursos que sea al menos igual al umbral de pobreza, es claro que la prestación deberá tener como cuantía estándar la que se entienda suficiente para poder afrontar esa situación elevando los recursos del sujeto o de la unidad de convivencia hasta el umbral de referencia. Aunque no deje de sorprender que, pese a las semejanzas con las pensiones no contributivas, el RDL 20/20 no contenga una regla similar de garantía de un mínimo, en el caso de que la diferencia entre el umbral de pobreza y los recursos sea inferior.

Hay, pues, vulnerabilidad económica, tal y como establece el art. 8 RDL 20/20, cuando el promedio mensual de los recursos del individuo (pero, particularmente, de la unidad de convivencia) sean inferiores, al menos en 10 euros, de la cuantía mensual de la propia prestación fijada en función de la modalidad y del número de miembros de la unidad de convivencia. De modo que la cuantía básica del IMV habrá de servir para establecer el umbral de pobreza individual, al tiempo que sirve de referencia para todas las modalidades de unidades de convivencia para las que la cuantía de la prestación se incrementará en función de su composición según se trate de mayores o de menores. A tal efecto, el art. 10 RDL 20/20, siendo éste un ejemplo más de la proximidad entre las prestaciones no contributivas y el IMV, toma como referencia la propia cuantía anual de esas pensiones que para el año 2020 es de 5.538 euros; lo que, dividido por las doce mensualidades, arroja una cantidad de 461,5 euros. Una cuantía, sin duda, muy reducida ya que no constituye más que el 41,63 por ciento de la cuantía anual del SMI y que necesariamente se verá incrementada, tal y como recoge el Anexo I de la norma, en función de la modalidad de la unidad de convivencia de que se trate. 
Es obvio, pues, que no es igual si se trata de una persona aislada o de una unidad de convivencia, dependiendo además de la configuración de la misma; tanto numérica lo que viene determinado por el número de personas que integran la unidad de convivencia si es que se vive en una de ellas y no de forma independiente, como cualitativa, es decir, si se trata, por ejemplo, de personas adultas o menores de edad y la proporción de unas y otras dentro de la unidad de convivencia ya que las necesidades mínimas de subsistencia varían de unos supuestos a otros. Lo que ya indica que el umbral de pobreza, y con él la cuantía de la prestación, partiendo de un montante o nivel fijo para el caso de una sola persona, debe subir o crecer a medida que aumenta el número de componentes de la unidad de convivencia y cambia la proporción de adultos o menores que se integran en ella. De ahí, como ya se ha dicho, la trascendencia del sujeto protegido en la nueva prestación del Sistema en la medida en que la configuración de la unidad de convivencia, típica o atípica, es determinante.

\section{El temor a la dependencia del subsidio: el énfasis en las medidas de retorno a la actividad productiva que hagan innecesario el IMV. El alcance matizado de la condicionalidad}

Como el IMV es un derecho de vigencia indefinida mientras subsistan las condiciones en las que fue reconocido, rasgo que comparte con las prestaciones de nivel no contributivo, y, por tanto, no sujeto a limitaciones presupuestarias o decisiones más o menos discrecionales del organismo de gestión, 1 IMV se presenta como una prestación sólida que atribuye al ciudadano una protección económica del Sistema cuando se encuentra en una situación de carencia de recursos.

Ya se ha dicho, pero conviene insistir, que el IMV forma parte del conjunto de prestaciones de garantía de recursos de subsistencia junto al resto de las prestaciones no contributivas y asistenciales del Sistema (esto es, pensiones de invalidez y jubilación y los variados subsidios asistenciales por desempleo) y de las prestaciones autonómicas de rentas mínimas. Pues bien, tradicionalmente, este tipo de prestaciones, y más concretamente en el caso de las autonómicas y de los diferentes subsidios de desempleo, han sido vistas por parte de muchos como unas prestaciones que tienen el riesgo de materializar la llamada trampa de la pobreza provocada, en gran medida, por la ausencia de estímulos para que el beneficiario de la prestación acepte ocupaciones o trabajos, mucho más si son precarias, a tiempo parcial o con una remuneración muy baja. De forma que se produce lo que se suele llamar como instalación en el subsidio siendo manifestación de la preferencia de los beneficiarios por mantenerse bajo el paraguas de la tutela asistencial antes que integrarse, con un coste de oportunidad muy alto, en el mercado de trabajo.

Pues bien, es evidente que el reconocimiento del IMV ha estado muy presionado por el objetivo de evitar que los perceptores de este tipo de prestaciones se conviertan en dependientes estables de la misma, desincentivando cualquier actividad o movimiento de salida de esa situación de pobreza y exclusión social mediante el desempeño de un trabajo o de una actividad retribuida de la que obtener, desplazando al IMV, los ingresos necesarios para su subsistencia personal y la de su núcleo de convivencia. Como también el riesgo de hacer crecer la economía sumergida si se establecen criterios en exceso rígidos que hagan imposible la compatibilidad legal entre prestación y trabajo, empujando a los perceptores del IMV a aceptar ofertas, que necesariamente han de ser irregulares, para preservar la obtención del IMV, combinando prestación con trabajo sumergido.

Pero no puede olvidarse que el IMV se configura, como lo dice expresamente el art. 3, d) del mismo RDL 20/20, como una red de protección dirigida a cubrir el tránsito desde la situación de exclusión a la de participación social. Lo que necesariamente implica el establecimiento sea de itinerarios que lleven, incluso forzadamente, al sujeto desde la posición de subsidiado a la de activo, sea de reglas que faciliten la compatibilidad del IMV con actividades retribuidas que, o bien sean 
de corta duración e inestables, o bien supongan ingresos de escasa cuantía, en el entendimiento de que, siendo rentas que proceden del esfuerzo personal de los beneficiarios por la integración y el retorno al mercado de trabajo y a la actividad, no deben ser penalizadas con la pérdida del subsidio.

De no ser así, la aceptación de las ofertas de trabajo o el desarrollo de una actividad profesional independiente dependerá del coste de oportunidad que estas posibilidades tengan; de forma que, si por un trabajo de corta duración que genera recursos escasos y no permanentes, se puede perder el IMV, es claro que la opción del interesado será rechazar esas ofertas o despreciar esas oportunidades para conservar el derecho al IMV, más interesante por cuantía y permanencia que esas alternativas de ocupación retribuida. Evitar, pues, este tipo de elecciones que frenan los procesos de inclusión social de los perceptores del IMV, y que funcionan como incentivo a la desocupación y a la dependencia del IMV para subsistir, constituye una preocupación del RDL 20/20, previendo medidas de activación profesional y de retorno al mercado de trabajo que pueden tener como consecuencia, si el beneficiario no se somete a ellas, la suspensión o pérdida de la prestación. Así lo prevé el RDL 20/20 en el capítulo dedicado a las obligaciones y sanciones

Sin embargo, hay que decir que el RDL 20/20 persigue estos objetivos de forma débil, estableciéndolos como tales en el texto legal, pero remitiéndose a un futuro desarrollo reglamentario en cuanto a la articulación de las exigencias y medidas concretas, así como de las consecuencias de las mismas en caso de incumplimiento. En todo caso, el RDL 20/20 hace indicaciones a esa normativa reglamentaria hablando, en cuanto a la posible compatibilidad de IMV y trabajo, de la naturaleza de la actividad y de las características del trabajo compatible, y también de límites que seguramente tengan que ver con la duración de la actividad y con los recursos que genera. Es posible imaginar cuál habrá de ser la línea de tendencia que seguirán las normas reglamentarias que se dicten; y que básicamente será la ya trazada por algunas de las normas autonómicas reguladoras de las rentas mínimas para las que razonablemente el objetivo de la activación profesional del beneficiario y el fomento de su empleabilidad queda matizado por aspectos tales como su edad, su cualificación y experiencia, así como por otros condicionantes personales. De forma que no necesariamente el reconocimiento, y sobre todo el mantenimiento del derecho a la prestación, está rígidamente condicionado por el desarrollo intenso de formas de activación profesional.

En cualquier caso, habrá que esperar al desarrollo reglamentario para apreciar en qué medida esta finalidad de retorno al mercado de trabajo y a la actividad profesional es, lo que no parece, el objetivo central del IMV; o si, por el contrario, su finalidad primera es proporcionar protección económica a quien se encuentra en situación de pobreza, siendo una medida protección a la que acompañan otras más relacionadas con las políticas de empleo.

\section{Conclusión}

La creación del IMV y su incorporación al cuadro de protección de nivel no contributivo supone un avance importante en la tutela del riesgo general de la pobreza; un territorio que hasta ahora, como se ha señalado, se encontraba prácticamente en manos de las CCAA. De este modo, la creación del IMV implica reconocer que es competencia del Estado la acción de tutelar la situación de necesidad económica real y efectiva de los ciudadanos. Al tiempo que, en tanto que derecho subjetivo, se consolida la posición jurídica del posible titular o beneficiario que podrá obtener la prestación siempre que reúna las exigencias previstas en la norma, tal y como sucede con el resto de prestaciones que integran el Sistema de Seguridad Social.

No obstante, la creación de este IMV no ha supuesto por sí misma la desaparición o eliminación de los mecanismos de cobertura asistencial desarrollados por las CCAA en el marco de sus 
competencias (art. 148.1.20 CE) habiéndose previsto en el RDL 20/20 reglas de compatibilidad al respecto. Aunque, como se ha dicho, es esperable que las CCAA finalmente destinen los recursos económicos de las prestaciones autonómicas de garantía de recursos, que hasta la creación del IMV constituían la última red de seguridad, a mejorar la nueva prestación del Sistema. Consiguiendo que, al menos, quienes se encuentren en situación de necesidad económica real y efectiva reciban la misma protección económica. Aunque siempre quepa la posibilidad de que las CCAA puedan mejorarla determinando que la cobertura final sea de mejor o peor condición en función de cuál sea la CA en que se resida.

La entrada del IMV en la esfera de la tutela pública del Sistema, y dentro de ella en el nivel no contributivo, permite pronosticar una reformulación de las actuales prestaciones de este nivel de protección social, simplificando así el confuso y espeso mundo de las actuales prestaciones de garantía de recursos de subsistencia caracterizadas por el elemento común de proteger la situación de carencia de recursos. No debe olvidarse que el objetivo del IMV no es otro que prevenir el riesgo de pobreza y exclusión social de las personas que vivan solas o integradas en una unidad de convivencia, siempre que se encuentren en una situación de vulnerabilidad por carecer de recursos económicos suficientes que les permita atender sus necesidades básicas. Por tanto, más allá de si además cuenta con un grado de discapacidad elevado, o de una edad avanzada e incluso, de si previamente ha desarrollado una actividad profesional previa como sucede en la protección asistencial de desempleo.

La creación del IMV, por otra parte, cierra de momento cualquier posible debate, por innecesario, acerca de la implantación de cualquier otro mecanismo con el que se pretenda atender la situación de necesidad más esencial del ciudadano cual es la pobreza; función que podría cumplir igualmente una renta básica en el sentido en el que antes se ha expresado. Cuestión distinta es que su regulación precise, por necesaria, además de la revisión y, en según qué casos reformulación del nivel asistencial de tutela pública, los correspondientes ajustes reglamentarios. El IMV, como se ha dicho al inicio de esta reflexión, no es una medida coyuntural, volátil o temporal, vinculada a la crisis sanitaria que se está padeciendo. Por el contrario, se consolida como un derecho subjetivo estructural más dentro de la Seguridad Social y, en consecuencia, con la estabilidad y permanencia que exige la protección frente a la pobreza. Que siempre, y más ahora en el contexto de la crisis económica derivada de la sanitaria, es una situación de necesidad que, en cuanto real y probada, reclama una cobertura sólida, suficiente y estable. 